\title{
Impact on Distribution System Protection with the Integration of EG on the Distribution Network
}

Jane Courtney

Technological University Dublin, jane.courtney@tudublin.ie

Aaron McDonnell

Technological University Dublin

Follow this and additional works at: https://arrow.tudublin.ie/engscheleart

Part of the Electrical and Electronics Commons

\section{Recommended Citation}

J. Courtney and A. McDonnell, "Impact on Distribution System Protection with the Integration of EG on the Distribution Network," 2019 54th International Universities Power Engineering Conference (UPEC), 2019, pp. 1-5, doi: 10.1109/UPEC.2019.8893563.

This Conference Paper is brought to you for free and open access by the School of Electrical and Electronic Engineering at ARROW@TU Dublin. It has been accepted for inclusion in Conference papers by an authorized administrator of ARROW@TU Dublin. For more information, please contact arrow.admin@tudublin.ie, aisling.coyne@tudublin.ie,gerard.connolly@tudublin.ie.

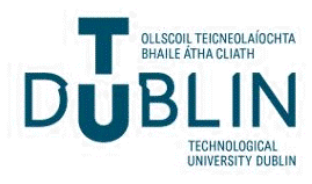




\section{Impact on Distribution System Protection with the Integration of EG on the Distribution Network}

\author{
Dr Jane Courtney \\ Dept of Electrical and Electronic Engineering \\ Technological University Dublin \\ Dublin, Ireland
}

\author{
Aaron McDonnell \\ Dept of Electrical and Electronic Engineering \\ Technological University Dublin \\ Dublin, Ireland
}

\begin{abstract}
A significant increase in EG connections on the distribution network over the past decade in Ireland has presented challenges to the Distribution System Operator (DSO). The connection of EG can cause co-ordination of Distance protection to be altered and has resulted in variations in short circuit levels. Multidirectional power flow has been introduced into a Distribution system that was not designed for the direction change in current flow. The impact of connecting EG to a typical $38 \mathrm{kV}$ Distribution Network was demonstrated as part of this study. Increasing fault levels and protection co-ordination selectivity problems were identified when the network was fed as a closed network. The increase in short circuit fault levels was evident when the fault contribution from the EG was considered. This increase in short circuit fault current could be a concern if EG is installed in an area where the maximum current rating of the switchgear could be exceeded. The co-ordination of Distance protection IEDs were also affected when EG was connected. Case studies on a typical Distribution Network were presented as part of this study. The impact that EG can have on the short circuit fault levels and the co-ordination of Distance protection when the network is feeding as a closed loop network was identified. When incorporating EG to a typical $38 \mathrm{kV}$ Distribution Network, considerations must be made to ensure that the connection of the EG does not inhibit the performance of the overall protection system. A protection review of the network is required before any EG is connected. The issues identified the miscoordination of Distance protection IEDs. A revision of current IED settings in the vicinity of the installed EG and the addition of duplicate protection IEDs may be required.
\end{abstract}

Index Terms-Distribution Network, Embedded Generation, Distance Protection co-ordination, Intelligent Electronic Device, Short Circuit Fault.

\section{INTRODUCTION}

The traditional components of a power system consist of a Power Plant, Transmission Network, Distribution Network and Customers. The power plant converts the energy from coal, oil, gas, wind and solar to electrical energy. In Ireland, the Transmission Network operates at $400 \mathrm{kV}, 220 \mathrm{kV}$ and 110 $\mathrm{kV}$. The voltage of the Distribution Network in Ireland $38 \mathrm{kV}$.
Before the connection of EG to the electricity network in Ireland, the network was operated radially with unidirectional power flow. As more EG was connected to the Distribution Network, the flow of electricity became increasingly bidirectional. In 2017 alone Ireland installed $426 \mathrm{MW}$ of new wind turbines, the majority of which were connected to the distribution network [1]. The bidirectional flow of electricity has presented challenges to power system protection [2]. As the operating principle has changed, this can cause issues such as false tripping and maloperation of protection. The decrease and increase in fault levels at specific locations on the grid prompted [2] to look at a case study into how some protection functions can be affected by EG connections to the distribution network, it outlined issues surrounding the underreaching and overreaching of relays. The primary form of protection applied to the distribution network in Ireland is Distance Protection [3]. Distance protection is the primary form of protection on feeders on the Distribution Network in Ireland. A voltage and current input measures the impedance on the feeder. If the current and voltage calculate a difference in impedance, the Distance protection IED will operate. The past 25 years have seen Irelands connections of EG increasing. As EG on the Irish distribution network is predominantly renewable, electricity generation in the form of wind power has been utilised. This increase in renewables is driven by the requirements from EU (RES-E directive 2009/28/EC) to reduce fossil fuel use and tackle the issue of climate change. Ireland has been set targets of $40 \%$ electricity production from renewables by 2020 [4]. Wind power will provide the majority of this $40 \%$ [5]. EG can assist in the reduction of Greenhouse Gas Emissions (GHG) through wind power and solar power [6]. Traditional fuel types used for centralised generation include oil and coal. Other EU Countries are currently developing plans to develop a more decentralized system for power generation. Denmark has recently changed its power system from a centralized system to a de-centralized system, mainly with the use of wind power [7]. There is currently 4,625 MW of wind capacity on the island of Ireland [8]. 
With the advent of EG, networks typically designed for radial power flow have become looped networks with unidirectional power flow [2][9][10][11][12]. Power distribution system expansion is increasing as the population grows; therefore, power system planners must ensure the increasing capacity meets the required load. EG can assist with the required system capacities [13]. The inclusion of EG to the distribution network in Ireland has forced the network operators to investigate how this bidirectional flow of power contributes to faults. This Distribution Network voltages and currents are not just dictated by loads but also EG. Rotating machines such as synchronous generators and induction generators are used for wind power and can cause an increase in fault levels to areas of the network that the equipment would not have been designed to withstand. In areas with large short circuit levels, the switchgear rating would already be close to being exceeded and the inclusion of EG would contribute to the rating being exceeded. Solutions are available to reduce the fault levels however this comes at a cost as expensive reactors can also increase losses and contribute to voltage variations [14].

\section{DistANCE PROTECTION}

\section{A. Distance Protection Performance}

Distance protection provides an economic and simple approach to protecting overhead lines and cable feeders. They operate on the principle of measuring the phase relationship between the operating and polarising quantity. Distance protection is a quick and dependable source of protection for the clearance of faults and provides selective tripping decisions [15]. A current transformer and voltage transformer input to the IED will provide necessary measurement quantities for the determination of a fault. Distance protection, if not correctly designed can be affected by various system conditions such as instrument transformer mis operation, changes in load, power swings and mutual coupling of transmission lines. These factors can be worsened by the introduction of EG [12]. Distance protection is used worldwide as a method of primary and back up protection on $38 \mathrm{kV}, 110 \mathrm{kV}$ and $220 \mathrm{kV}$ Transmission lines [16]. Distance protection is the most utilised form of protecting feeders on Irelands $38 \mathrm{kV}$ distribution network [2].

\section{B. Protection and Embedded Generation}

The inclusion of EG to the distribution network can increase reliability of power networks. However, power system protection can be severely impacted with this inclusion [17]. EG contributes to a higher fault current seen by protection relays [8][14]. The inclusion of EG can affect the grading margin between protection relays on a feeder. In [10] the penetration of EG resulted in the slower operation of protection relays which lead to protection blinding. Protection blinding was identified on studies of the distribution network in [9] and [10].

In [10] it was described how a large penetration of EG affected the protection systems on the distribution network in Malaysia. By connecting EG, lower grid infeed and larger currents during fault conditions were identified. IDMT elements of the overcurrent relay became less sensitive. Grading margins were affected resulting in non-operation in some recorded cases.

Classic protection schemes have been identified as inadequate in providing protection for systems originally designed for passive and radial networks. [19] introduced a solution for improving protection reliability with the increase in EG through flexible network configurations and islanding. Advanced and adaptive protection for distribution networks have been identified as a method to improve protection reliability [20]. Proposed solutions utilise IED's with appropriate communication systems. Proposals include using line sensors for the fast interruption of faults with communication, phase measurement units and the use of measurement capable devices for zone protection [19][21].

Connecting EG to the Distribution network can introduce problems with selectivity and coordination of protection devices and to ensure correct safety and operation of the network, a full protection analysis is recommended by [9] before installing EG on a Distribution network. In [22][23] it was recommended to upgrade protection devices in the event that fuses are still in operation and to ensure a protection study is undertaken to analyse the impact of short circuit currents on the protection devices and the power system equipment. It may be the case that IED protection settings are to be revised and upgraded to account for the inclusion of EG [12][24]. Networks previously configured for radial flow can be changed to open loop or closed loop to account for further integration of EG. This change in configuration increases the reliability of the network [25] [26].

\section{POWER SYSTEM MODEL}

The network illustrated in figure 1 is a typical distribution network feeding arrangement and topology. There is a total of 5 buses connected in a closed loop arrangement. Typically, the buses would be in a substation and would consist of measuring and protection equipment. The network configuration incorporates the following:

- 1 x 110/38 kV Transformer

- 1 x Embedded Generator

- 4 x Transmission Lines

- 2 x Loads

- 5 Buses

- $\quad 12$ Circuit Breakers

- 4 x Protection IEDs

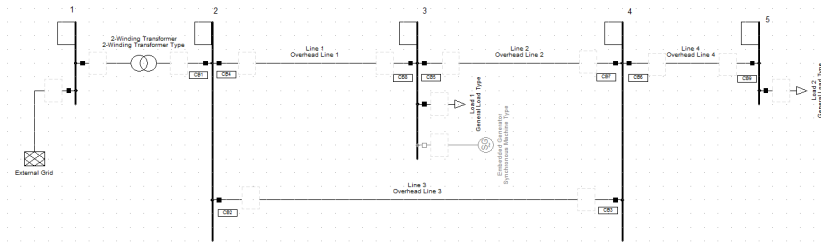

Figure 1: Power System Model 
A CB protects each line connected to each bus; the $\mathrm{CB}$ will open in the event of a fault detected by a protection IED. The network shown in figure 1 is a $38 \mathrm{kV}$ network, similar in topology to a section of the distribution network in Ireland. The $38 \mathrm{kV}$ network is connected to the transmission network via a $110 / 38 \mathrm{kV}$ Transformer. The $110 / 38 \mathrm{kV}$ transformer is connected between bus 1 and bus 2. This is the Bulk Supply Point (BSP) that services Load 1 and Load 2 connected to Bus 3 and Bus 5 respectively. The supply is transferred through overhead lines connected between each bus. EG was positioned on bus 3 to show how this connection of EG on the distribution network might have an effect of the fault levels and Distance protection in this section of the network in a closed loop configuration.

\section{RESULTS}

\section{A. Short Circuit Fault Analysis}

The power system was modelled in a power system modelling software called DigSilent Power factory to analyse the fault current on each bus when EG is connected to a typical Distribution Network. Transmission lines, generators, transformers and loads were modelled with their positive, negative and zero sequence impedances. The fault analysis section investigates the effect of short circuit fault levels in a closed loop feeding arrangement. The results are for a LineLine-Line fault in kA. The symmetrical current Ik" was the value considered for this study. The system feeds the Load connected to Bus 3 and Bus 5 from the BSP via line 1 and line 2 . In this case the EG at bus 3 is modelled as connected and not connected. This is a closed loop feeding arrangement.

Short Circuit Fault Analysis Results

In the event of a short circuit between three phases it can be observed that there is a clear increase in the current magnitude. recorded on the buses when EG is connected. As shown from figure 1 above, adding EG to the network can result in increases to the fault current. All buses show increases in fault currents when EG is connected on bus 3 for all fault types. A Line-Line fault on bus 3 has a $43 \%$ increase in fault current when the generation is connected. Bus 2, $4 \& 5$ have increases in fault current above $39 \%$ of the fault current with EG connected.

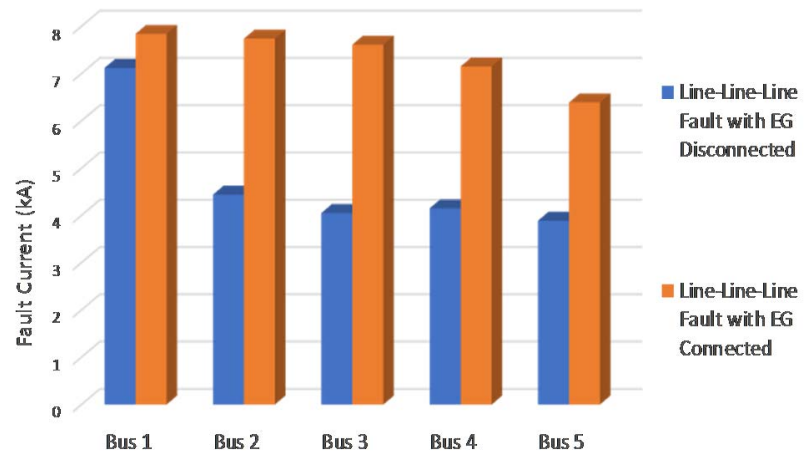

Figure 2: Short Circuit Fault Current on each bus of the Power System Model

\section{B. Impedance Protection co-ordination}

The power system protection was modelled in a software called CAPE (Computer Aided Protection Engineering) to analyse the effect on protection co-ordination of the protection relays when EG is connected to a typical Distribution Network. The impedance protection co-ordination section investigates how the IED operates in the event of a fault. It shows the coverage each zone has on a feeder for each IED and the time it will operate if a fault occurs on the line. The system feeds the Load connected to Bus 3 and Bus 5 from the BSP via line 1 and line 2. In this case the EG at bus 3 is modelled as connected and not connected. This is a closed loop feeding arrangement.

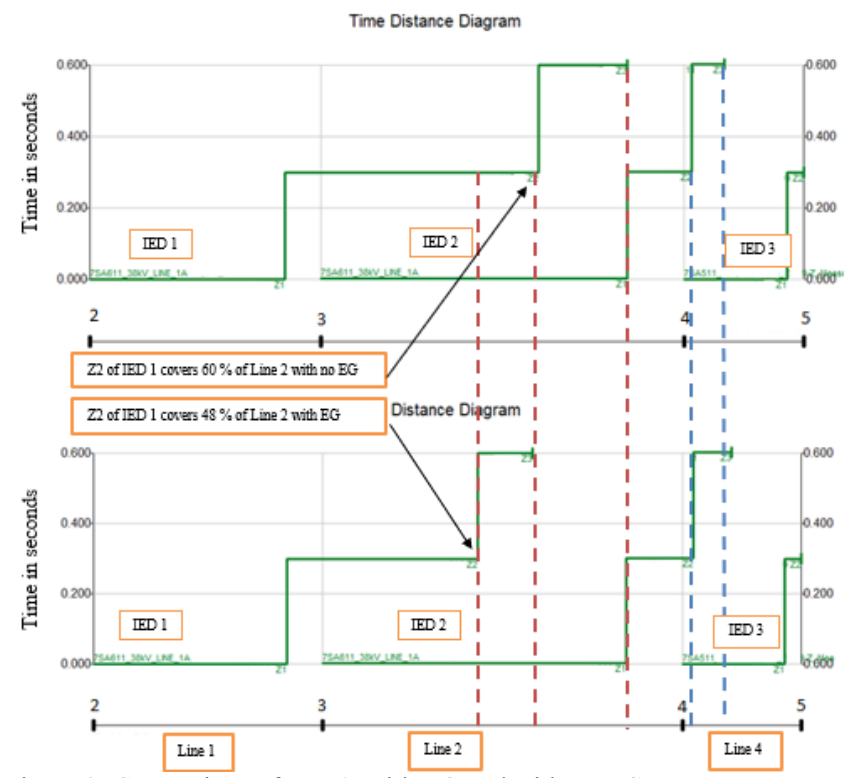

Figure 3: Comparison of TDD's with EG and without EG

1) Protecion coordination Results

Figure 3 shows the differences in zone reach when the network is feeding as a closed looped system with and without EG connected. The upper TDD is when EG is not connected and the lower TDD is when EG is connected. Figure 3 illustrates how the connection of EG affects the coordination of the protection IEDS in this configuration. Zone 2 and Zone 3 of the IEDs are underreaching when the EG is connected resulting in a deficit of coverage caused by the introduction of EG on the network. The zone 2 of IED 1 covers as far as $60 \%$ of the line from Bus 3 to Bus 4 with no EG. However, when EG is connected zone 2 of IED 1 only covers $48 \%$ of the line. The zone 3 of IED 1 covers as far as $85 \%$ of the line from Bus 3 to Bus 4 with no EG. However, when EG is connected zone 3 of IED 1 only covers $58 \%$ of the line. There is clear underreaching present caused by the introduction of EG. The upper TDD has coordination, as each zone of one IED stops as another zone of the other IED starts, $300 \mathrm{~ms}$ later. When EG is connected the zones do not coordinate and there is a section of the network where there is no back up protection available in the event of a fault. 


\section{DISCUSSION}

The inclusion of EG generation in this network configuration demonstrated an increase in fault current magnitude. The fault contribution of the EG increased the fault current up to $40 \%$. The sample $38 \mathrm{kV}$ distribution network configuration shown in this study can be operated as a closed loop or a radial feeding network depending on the current requirements of the network. A normally fed closed loop system can be fed as a radial network in the event of a planned or unplanned outage on one of the Transmission lines. Increasing fault levels can introduce problems if the maximum short circuit strength of the switchgear is not rated to withstand the increase in fault current. When planning the inclusion of EG to a network, an overall short circuit study must be completed to ensure that under maximum loading conditions the switchgear on the network can withstand the increases. If it's the case that the switchgear is not rated for the increase in fault current, it can be expensive replacing the equipment, therefore a short circuit study would be implemented in the planning stages.

An increase in fault levels can affect the selectivity and reliability of the system protection in the area. IEDs downstream of a fault will provide backup protection in the event the primary protection fails. This back up protection is severely affected by the inclusion of EG on this network. It was discovered that if the EG is operating at full when a fault occurs and the primary protection failed, the backup protection relay would be unable to pick up and operate the $\mathrm{CB}$ on parts of the line. This maloperation can cause serious damage to equipment and could result in a significant portion of the network being affected with an unplanned outage. To counter act this affect the settings of the IEDs could be revised and a protection coordination study could be undertaken to plan for this issue. Revised settings can have knock on affect to the coordination of other IEDs on the network, resulting in a requirement of IED setting changes for multiple IEDs. A full protection review would be undertaken to see how this issue could be mitigated; however, a full review would not completely eradicate the issue. Selectivity, reliability and speed can all be affected by this change in IED settings.

The cases presented showed underreaching and overreaching issues of protection zones affecting the speed and reliability of the protection system. When EG was connected the correct coordination of the protection was not fulfilled.

\section{CONCLUSION}

The objective was to identify issues surrounding short circuit fault levels and issues with the co-ordination of Distance protection on a typical distribution network when EG was incorporated into the network. The impact of connecting EG to a typical $38 \mathrm{kV}$ Distribution Network was demonstrated as part of this study. Increasing fault levels and protection coordination selectivity problems were identified when the network was fed as a closed network and as a radial fed network. The increase in short circuit fault levels was evident when the fault contribution from the EG was considered. This increase in short circuit fault current could be a concern if EG is installed in an area where the maximum current rating of the switchgear could be exceeded. The co-ordination of Distance protection relays was also affected when EG was connected. Underreaching was evident, which resulted in feeders not having the required back up protection. Not having the required backup protection breaks the rules set out by the utility in Ireland, ESB Networks. This underreaching of protection IEDs can be mitigated by changing the settings of the IED or by installing duplicate protection on the protected feeder. When incorporating EG to a typical $38 \mathrm{kV}$ Distribution Network, considerations must be made to ensure that the connection of the EG does not inhibit the performance of the overall protection system. A protection review of the network is required before any EG is connected. A revision of current IED settings and the addition of new protection IEDs' may be required to be installed.

The issues demonstrated in this paper are in line with current literature. Adding EG to the proposed Distribution Network will affect the following:

- Coordination of protection IEDs

- Will introduce bidirectional power flows

- Increase in short circuit fault levels

- $\quad$ Selectivity, reliability, speed and stability issues of Distance protection IEDs

\section{REFERENCES}

.[1] J. Whelan, J. Kelleher, A. Mcdonnell, and S. Hunt, "Wind Farm Fault Ride Through - An Irish Context," 17th Int. Wind Integr. Work., no. October, 2018.

[2] T. Gallery, L. Martinez, and D. Klopotan, "Impact of Distributed Generation on Distribution Network Protection," ESBI Eng. Facil. Manag. ..., vol. 2005, pp. 478-482, 2005.

[3] Electricity Supply Board, "Distribution System Protection Policy," Dublin, 2005.

[4] DCENR, "Ireland's Transition to a Low Carbon Energy Future 2015-2030," p. 122, 2015.

[5] C. Johns and J. Power, "Wind Energy in the context of Ireland 's Energy Wind Energy in Ireland," p. 28, 2015.

[6] J. Kennedy, P. Ciufo, and A. Agalgaonkar, "A review of protection systems for distribution networks embedded with renewable generation," Renew. Sustain. Energy Rev., vol. 58, pp. 1308-1317, 2016.

[7] F. Blaabjerg, Y. Yang, D. Yang, and X. Wang, "Distributed PowerGeneration Systems and Protection," Proc. IEEE, vol. 105, no. 7, pp. 1311-1331, 2017.

[8] SEAI, "Energy in Ireland key statistics." Sustainable Energy Authority Ireland, Dublin, 2018.

[9] P. M. Koumba and A. C. Mamadou Lamine Doumbia, "Impacts of Distributed Generation on the Coordination of Protective Devices in Distribution Network," IEEE Conf. Electr. Comput. Eng., vol. IEEE 28 th, no. 978-1-4799-5829-0/15, p. 6, 2015.

[10] A. Ali, F. Buderi, M. Hanafiah, and A. Baharudin, "Generation to the Distribution Network Overcurrent Protection in Malaysia," 2016 IEEE Int. Conf. Power Energy, pp. 361-365, 2016.

[11] F. Gu, "Impact of Distributed Generation on Relay Protection and Its Improved Measures," IEEE, pp. 1-5.

[12] V. P. Mahadanaarachchi, S. Member, R. Ramakumar, and L. Fellow, "Impact of Distributed Generation on Distance Protection Performance - A Review," IEEE, pp. 1-7, 2008.

[13] M. Fotuhi-firuzabad, "Embedded Generation Planning in Presence of Renewable Resources Using a Probabilistic Multi-Objective Planning Approach," CIRED, vol. Paper 0260, no. May, pp. 1-4, 2012.

[14] N. Jenkins, R. Allan, P. Crossley, D. Kirschen, and G. Strbac, 
Embedded Generation. London: The Institution of Electrical Engineers, 2000.

[15] Y. Zhong, X. N. Kang, and Z. B. Jiao, "A Novel Distance Protection Algorithm for Long-Distance Transmission Lines," 12th IET Int. Conf. Dev. Power Syst. Prot. (DPSP 2014), pp. 1-5, 2014.

[16] C. Wang, G. Song, and J. Tang, "Protection Performance of Traditional Distance Relays Under Wind Power Integration," 13th Int. Conf. Dev. Power Syst. Prot. 2016, pp. 1-5, 2016.

[17] D. K. Jain, P. Gupta, and M. Singh, "Overcurrent protection of distribution network with distributed generation," 2015 IEEE Innov. Smart Grid Technol. - Asia (ISGT ASIA), pp. 1-6, 2015.

[18] H. Ha and S. Subramanian, "Predicting the prospective fault level on distribution grids and its impact on protective relaying," IEEE. p. 4

[19] S. Venkata, D. Wilson, J. Ren, and M. Milller, "Advanced and Adaptive Protection for Active Distribution Grid," Cired, 22nd Int. Conf. Electr. Distrib., vol. Cired 2013, no. Paper 1312, p. 4, 2013.

[20] M. Yang and Y. Zhu, "Study on adaptive Distance Protection Using Multi Agent Technology," 2005 Int. Power Eng. Conf., vol. Vol. 2, p. Pages: 618-622, 2005.

[21] B. J. Brearley and R. R. Prabu, "A review on issues and approaches for microgrid protection," Renew. Sustain. Energy Rev., vol. 67, pp. 988-997, 2017.
[22] A. H. Reza, "New Method on the Relays Protective Coordination Due To Presence Of Distributed Generation," 2012 Power Eng. Autom. Conf., pp. 1-4, 2012.

[23] E. Purwar, D. N. Vishwakarma, and S. P. Singh, "Planning A Comprehensive Protection Scheme Considering Distributed Generation," IEEE, p. 6file://D:/USB Back up/College/Thesis/Research Pa.

[24] W. Rojewski, Z. A. Styczynski, and J. Izykowski, "Selected Problems of Protective Relaying for Distribution Network with Distributed Generation," 2009 IEEE Power Energy Soc. Gen. Meet., pp. 1-6, 2009.

[25] S. K. Salman, S. F. Tan, and T. Robert, "High Penetration of Embedded Generation Using Radial and Ring Operation Mode," IEEE, pp. 6-10.

[26] B. Li, X. Yu, Z. Bo, and S. Member, "Protection Schemes for Closed Loop Distribution Network with Distributed Generator," 2009 Int. Conf. Sustain. Power Gener. Supply, no. 08, pp. 1-6. 